\title{
IMPLICAÇÕES CULTURAIS NO PLANEJAMENTO FAMILIAR E QUALIDADE DE VIDA DA MULHER/FAMÍLIA E A TEORIA DE LEININGER*
}

Elizabeth Maria Fernandes Cortez ${ }^{1}$, Ivete Palmira Sanson Zagonel ${ }^{2}$

RESUMO: Pesquisa qualitativa que utilizou o método exploratório-descritivo e teve como objeto de estudo as implicações culturais no planejamento familiar, sua interface com a qualidade de vida da mulher/família e a Teoria de Leininger. Foram objetivos investigar o conhecimento, facilidades e dificuldades na implantação de estratégias de planejamento familiar e delinear as implicações culturais das ações contraceptivas adotadas e sua interface na qualidade de vida da mulher/família. Para a coleta de informações foi utilizada a entrevista semiestruturada com 20 mulheres, no período de agosto a outubro de 2008. A análise de conteúdo temática apontou os aspectos culturais como fortemente evidenciados para o planejamento familiar, o que denota que as diversas conformações de família têm seu modo próprio de viver e administrar conceitos de cuidado à saúde. Os padrões de cuidado desenvolvidos por Leininger, como preservar, acomodar ou repadronizar, proporcionaram reflexão, conscientização e respeito aos valores e crenças da mulher/família.

PALAVRAS-CHAVE: Cuidados de enfermagem; Planejamento familiar; Família; Cultura.

\section{CULTURAL IMPLICATIONS IN FAMILY PLANNING AND QUALITY OF LIFE OF THE WOMAN AND FAMILY, AND LEININGER'S THEORY}

\begin{abstract}
: qualitative research which utilized the exploratory-descriptive method and had as its study cultural implications in family planning, their interface with women's and families' quality of life, and Leininger's Theory. Objectives were to investigate knowledge, facilities and difficulties in implanting family planning strategies and to delineate the cultural implications of contraceptive actions adopted and their interface with the quality of life of the woman and family. Data collection was via semistructured interviews with 20 women, between August and October 2008. Thematic content analysis pointed to cultural aspects as heavily in evidence in family planning, which indicates that the diverse family configurations have their own way of living and administrating concepts of health care. The patterns of care developed by Leininger, such as preserving, accommodating or restandardizing, provide reflection, consciousness raising and respect to the values and beliefs of the woman and/or family. KEYWORDS: Nursing care; Family planning; Family; Culture.

\section{IMPLICACIONES CULTURALES EN EL PLANEAMIENTO FAMILIAR Y CUALIDAD DE VIDA DE LA MUJER/FAMILIA Y LA TEORÍA DE LEININGER}

RESUMEN: Investigación cualitativa que utilizó el método exploratorio descriptivo y tuvo como objeto de estudio las implicaciones culturales en el planeamiento familiar, su interfaz con la cualidad de vida de la mujer/familia y la Teoría de Leininger. Fueron objetivos investigar el conocimiento, facilidades y dificultades en la implantación de estrategias de planeamiento familiar y delinear las implicaciones culturales de las acciones contraceptivas adoptadas así como su interfaz en la cualidad de vida de la mujer/familia. Para recoger las informaciones fue utilizada la entrevista semiestructurada con 20 mujeres, en periodo de agosto a octubre de 2008. El análisis de contenido temático reveló aspectos culturales como fuertemente evidenciados para el planeamiento familiar, lo que muestra que las diversas conformaciones de familia tienen su modo propio de vivir y administrar conceptos de cuidado a la salud. Los patrones de cuidado desarrollados por Leininger, como preservar, acomodar o reestandarizar, proporcionaron reflexión, conscientización y respeto a los valores y crencias de la mujer/familia.

PALABRAS CLAVE: Cuidados de enfermería; Planeamiento familiar; Familia; Cultura.

*Extraído da monografia de conclusão do Curso de Graduação em Enfermagem das Faculdades Pequeno Príncipe - FPP. ${ }^{1}$ Enfermeira. Especializanda em Gestão em Serviços de Saúde - FPP.

${ }^{2}$ Enfermeira. Doutora em Enfermagem. Professora do Curso de Graduação em Enfermagem e do Programa de PósGraduação em Biotecnologia Aplicada à Saúde da Criança e do Adolescente - FPP. Líder do Núcleo de Estudos, Pesquisa e Extensão em Enfermagem.

\author{
Autor correspondente: \\ Elizabeth Maria Fernandes Cortez \\ Faculdades Pequeno Príncipe \\ Endereço: Av. Silva Jardim, 994 - 80230-000 - Curitiba-PR-Brasil. \\ E-mail: bethinha77@yahoo.com.br
}

Recebido: 07/11/10

Aprovado: 31/03/11 


\section{INTRODUÇÃO}

O planejamento familiar, como ação de saúde, é reconhecido como uma necessidade do ser humano, porém apresenta controvérsias entre o que é praticado pela sociedade e o que é estabelecido nas normas do Estado e, sobretudo, o que é disponibilizado pelos serviços de saúde. O Poder Legislativo também reconhece a importância da matéria e por ele tramitam dezenas de projetos de lei regulamentando ou ampliando permissivos legais sobre o assunto. Embora avançadas em seus princípios, conteúdos e diretrizes, as políticas públicas propostas pelo Executivo são reticentes na sua implantação ${ }^{(1)}$.

A legislação brasileira estabelece que as instâncias gestoras do Sistema Único de Saúde (SUS), em todos os seus níveis, estão obrigadas a garantir à mulher, ao homem ou ao casal, em toda a sua rede de serviços, assistência à concepção e contracepção. Essa faz parte das demais ações que compõem a assistência integral à saúde ${ }^{(2)}$.

Com o progresso, descobertas científicas e o avanço da tecnologia, torna-se imprescindível adotar o planejamento familiar em diversas ou quase todas as questões e iniciativas da vida humana. O trabalho em saúde da família, como modelo de atenção primária, deve considerar a família como locus básico de atuação. As técnicas utilizadas para executar o trabalho devem basear-se na realidade local, construindo um fazer consistente que implique na melhoria dos indicadores de saúde da comunidade e satisfação, não apenas da população atendida, como também da equipe que executa a proposta ${ }^{(3)}$.

O planejamento familiar é parte integrante de um conjunto de ações educativas prioritárias à mulher/ família, dentro de uma visão de atendimento global e integral à saúde. Consideramos essencial entender, por meio da mulher/família, quais as implicações culturais que afetam o planejamento familiar. Neste estudo, procuramos entender não apenas a mulher, mas também a família, considerando seus pontos de vista e conhecimentos que vêm sendo elaborados no decorrer de sua existência sobre a questão do planejamento familiar.

Assim sendo, este estudo visa alertar para ações de cuidado cultural que privilegiem o ser humano, tendo como sujeitos a mulher e sua família, uma unidade complexa que necessita de atenção especial e diferenciada para alcançar a qualidade de vida.

Pressupomos que para cuidar da saúde do ser humano não devemos somente considerar os conceitos de prevenção, diagnóstico e tratamento, mas conhecer o contexto cultural, os valores, crenças e rituais e, sobretudo, o modo de vida da mulher e sua família, principalmente ao tratar do tema de planejamento familiar.

Assim, para subsidiar este estudo, buscamos nas ideias da Teoria da Diversidade e Universalidade do Cuidado Cultural, proposta por Leininger ${ }^{(4)}$, a sustentação para conhecer cada sujeito partícipe da pesquisa e seus preceitos culturais, seu modo de vida. Para então, delinear formas de enfrentamento e implementação de práticas que fortaleçam a mulher/família para o efetivo desempenho do processo de decisão no planejamento familiar.

O estudo teve como objetivos investigar junto à mulher/família o conhecimento, facilidades e dificuldades na implantação de estratégias de planejamento familiar, de acordo com seu contexto cultural de vida; e delinear as implicações culturais das ações contraceptivas adotadas no planejamento familiar e sua consequente interface com a qualidade de vida da mulher/família.

\section{REFERENCIAL TEÓRICO}

A contracepção cresceu muito no século XX, a partir da orientação oferecida por instituições privadas que foram surgindo na Inglaterra, com a liderança de Marie Stopes, e nos Estados Unidos, com a liderança de Margaret Sanger.

A denominação incial "controle de natalidade" vulgarizou-se como se fosse um rótulo para identificar a ação de uma pessoa no controle da necessidade reprodutiva. Pouco depois, considerou-se que tal termo seria inadequado por sugerir caráter compulsório da definição de quantos filhos o casal poderia ter. Optouse, assim, pela denominação planejamento familiar, mostrando o aspecto positivo de que a pessoa definiria com soberania a época de nascimento dos filhos e o seu número ${ }^{(5)}$.

O planejamento familiar (PF) é uma ação de saúde, de proteção da mulher/família para que possa decidir o número e espaçamento de filhos, a fim de manter a vida saudável e em condições de oferecer cuidado apropriado aos filhos. $\mathrm{O}$ conceito tem mudado nos últimos anos, acompanhando a evolução mundial pautada pelas diversas Conferências Internacionais. Assim, de um conceito estreitamente ligado à ideia de limitação ou espaçamento dos nascimentos, evolui-se para contracepção como prevenção de uma gravidez não desejada; alargou-se também o âmbito das ativi- 
dades com o Decreto Lei de 3/84 para a Prevenção de Doenças de Transmissão Sexual. Em 1985, iniciou-se a Avaliação das Atividades de PF com Inquéritos sobre a Fecundidade e Família ${ }^{(6)}$.

Com a evolução das mudanças socioculturais e demográficas, as expressões saúde materna e planejamento familiar, tradicionalmente usadas em saúde pública, tornaram-se demasiado estreitas para conter as preocupações atuais referentes à área de saúde. Assim, as mulheres reclamam o direito de ver as suas necessidades em saúde encaradas numa perspectiva de mulheres, e não meramente de mães.

A Enfermagem é essencialmente uma profissão de cuidados transculturais, pois centra-se na promoção do cuidado humano para pessoas de uma maneira significativa, respeitando os valores culturais e estilos de vida. A Teoria de Leininger foi desenvolvida a partir da Antropologia, porém reformulada para Enfermagem Transcultural, com perspectivas de cuidado humanizado $^{(4)}$. Este fato é confirmado:

[...] o cuidado é o domínio central e o único para o corpo de conhecimentos e prática na Enfermagem, e uma investigação sistematizada do cuidado poderá avançar a disciplina de Enfermagem e em último caso, prover cuidados de enfermagem melhores para o povo ${ }^{(7: 35)}$.

A demanda por PF não é universal e tampouco aceita por culturas diferentes; existem muitas razões para isso, pois na maioria dos casos o PF está intimamente ligado ao valor dado aos filhos. Em determinadas culturas, ter uma criança é sinal visível de status para o adulto. Nessas comunidades, em que são comuns a fome, a pobreza, a insegurança e um alto índice de mortalidade infantil, a fertilidade adquire alto valor social, ter muitos filhos é um dos poucos modos de as pessoas assegurarem seu futuro ${ }^{(8)}$.

O cuidado cultural, dessa forma, é o meio holístico mais amplo para conhecer, explicar, interpretar e prever o fenômeno do atendimento de enfermagem, visando orientar suas práticas de cuidado ${ }^{(9)}$. Neste sentido, os profissionais de saúde devem estar preparados técnica e cientificamente, assumindo o paradigma que determina a sistematização global do saber humanizado, visualizando o cliente como único em todas as suas necessidades.

É necessário conhecer o contexto cultural das pessoas de quem cuidamos para que as ações de saúde alcancem o resultado esperado. Também é primordial "compreender que o processo saúde-doença sofre influências multifatoriais dentro de um contexto social $^{\prime(10: 15)}$.

\section{METODOLOGIA}

Este estudo adotou abordagem qualitativa, por meio do método exploratório-descritivo, que permite levantar problemáticas com base em uma realidade vivenciada. Este tipo de pesquisa permite salientar os aspectos dinâmicos, holísticos e individuais da experiência humana, bem como apreender tais aspectos em uma totalidade, no contexto daqueles que os estão vivenciando ${ }^{(11)}$.

Fizeram parte do estudo 20 mulheres cadastradas na Unidade de Saúde Capanema da Secretaria Municipal da Saúde (SMS) de Curitiba, Estado do Paraná. Como critérios de inclusão as mulheres deveriam estar cadastradas na Estratégia Saúde da Família (ESF) e ter filhos; independentemente do estado civil, ocupação, escolaridade ou idade, bem como aceitar e formalizar a sua participação no estudo.

Para a coleta das informações, realizada de agosto a outubro de 2008, utilizamos a entrevista semiestruturada, gravada, previamente agendada e realizada na própria Unidade de Saúde, a qual transcorreu com interação da mulher e pesquisadoras, para possibilitar uma maior informalidade com relação ao assunto proposto.

O instrumento contemplou questões sóciodemográficas e questões do contexto específico do PF para elucidar a questão norteadora: Quais as implicações culturais no planejamento familiar e sua interface com a qualidade de vida das mulheres/ famílias? As informações obtidas foram analisadas pela análise de conteúdo temática, composta pelas fases de ordenação dos dados, classificação dos dados e análise final ${ }^{(11)}$.

Atendendo aos propósitos do estudo, foram respeitados os princípios éticos de pesquisa envolvendo seres humanos, conforme a Resolução 196/96 do Conselho Nacional de Saúde ${ }^{(12)}$. A pesquisa foi aprovada pelo Comitê de Ética do Hospital Pequeno Príncipe com o parecer n. 152/08, bem como pelo Comitê de Ética da SMS de Curitiba. As participantes receberam nomes de frutas para manter o anonimato, seguidos da idade.

\section{RESULTADOS}

A idade média das mulheres entrevistadas variou de 19 a 46 anos, sendo que houve prevalência da faixa etária de 20 anos. Oito eram casadas, seis com união estável, cinco solteiras e uma divorciada. Quanto à 
ocupação, quatro eram catadoras de papel, cinco do lar, três trabalhavam com reciclagem de plástico, duas eram domésticas, duas auxiliares de serviços gerais, uma técnica em enfermagem, uma profissional do sexo, uma vendedora e uma confeiteira.

A partir das transcrições e ordenação dos dados, realizadas a leitura e releitura dos depoimentos e constituição de um corpus de conhecimento, foram encontradas 7 categorias e 16 subcategorias determinando a classificação dos dados. Após a categorização chegamos à análise final que consiste no ponto de partida e de chegada da compreensão e interpretação dos discursos.

Para fins deste artigo destacamos cinco categorias com algumas de suas subcategorias conforme o quadro 1 .

Quadro 1 - Representação das categorias e subcategorias sobre Planejamento Familiar. Curitiba, 2008

\begin{tabular}{|c|c|}
\hline CATEGORIAS & SUBCATEGORIAS \\
\hline O significado do planejamento familiar & Consciência da importância do planejamento familiar \\
\hline Articulação do planejamento familiar com a qualidade de vida & Uma luz de como fazer para obter a qualidade de vida \\
\hline $\begin{array}{l}\text { O conceito de família e cultura sob a ótica da mulher rela- } \\
\text { cionado ao planejamento familiar }\end{array}$ & $\begin{array}{l}\text { Família é a base de tudo: é onde as pessoas se organizam } \\
\text { para viver junto }\end{array}$ \\
\hline Aderência ao programa de planejamento familiar & $\begin{array}{l}\text { A percepção do acolhimento da equipe de enfermagem } \\
\text { Facilidades e dificuldades percebidas diante do planejamento } \\
\text { familiar }\end{array}$ \\
\hline $\begin{array}{l}\text { Auxílio da equipe de enfermagem e de saúde no planeja- } \\
\text { mento familiar }\end{array}$ & Facilidade de acesso aos métodos \\
\hline
\end{tabular}

\section{DISCUSSÃO}

A categoria O significado do Planejamento Familiar, e a subcategoria Consciência da importância do planejamento familiar, apontam que o significado exposto pelas mulheres entrevistadas envolve a consciência da importância do planejamento familiar, porém refere que nem todas as mulheres seguem as orientações recebidas na Unidade de Saúde. As participantes salientam como importante, a inclusão do companheiro na decisão de planejar a família, considerando que, para dar certo, esta ação deve ser em conjunto. Ter filhos ou constituir uma família necessita de base, de estrutura:

Acho uma boa. Conheço o programa, apesar de que as pessoas não seguem o que os postos ensinam, mas todos deviam fazer e seguir. Não adianta escutar $e$ não seguir porque o problema é ter filho e não cuidar. (Morango, 40 anos)

O significado do PF surgiu pela necessidade de estruturação familiar, controle efetivo da fertilidade, sexo seguro, quando e com quem ter filho, sendo que tal planejamento traz repercussões socioeconômicas importantes para a mulher como estudos, carreira profissional, mercado de trabalho efetivo. Ou seja, uma realização completa como mulher e mãe, já que a atividade sexual precoce traz consequências importantes, tanto no âmbito do conhecimento, quanto da conscientização e maturidade ${ }^{(13)}$. Esta categoria tem estreita relação com o primeiro nível do Modelo Sunrise da Teoria de Leininger ${ }^{(5)}$, no qual são avaliados aspectos da estrutura social e a visão de mundo da cultura das mulheres. Incluem-se ainda, o contexto ambiental, parentesco, valores e crenças culturais, sistema legal, economia e educação.

Na categoria Articulação do Planejamento Familiar à qualidade de vida e na subcategoria Uma luz de como fazer para obter a qualidade de vida os depoimentos indicam que a qualidade de vida está relacionada ao menor número de filhos, ao tipo de ocupação que as mulhres desenvolvem, às perspectivas de vida futura, à boa alimentação, às condições de prevenção das doenças sexualmente transmissíveis e da gravidez indesejada e ao acesso a serviços de saúde.

[...] porque quanto mais filho, a qualidade de vida é[...] bem sofrida, e se tem pouco filho é melhor [risos] dá pra dar de comer a todos e comprar mais coisas pra casa, e todos com saúde. (Morango, 40 anos)

Qualidade de vida é um conceito subjetivo, pois é a pessoa que melhor pode definir sua própria qualidade de vida e relatar suas expectativas, satisfação e bemestar. Aqui é possível perceber que o primeiro nível do Modelo Sunrise da Teoria de Leininger está presente, 
que todos os aspectos que permeiam a estrutura cultural e social das mulheres/famílias sofrem a influência de padrões de cuidado e de expressões que referem-se como bem-estar e saúde.

Na categoria $\mathbf{O}$ conceito de família e cultura sob a ótica da mulher relacionado ao planejamento familiar e na subcategoria Família é a base de tudo: é onde as pessoas se organizam para viver junto, as mulheres apontam que a família é união, compartilhamento das experiências e companheirismo; os conceitos familiares são repassados de geração em geração como algo positivo, como algo que contribui.

A família corresponde a um lugar privilegiado de afeto, no qual estão inseridos relacionamentos íntimos, expressão de emoções e de sentimentos ${ }^{(14)}$. Essa também envolve os momentos de conflito, enfatizando que estes aspectos fazem parte da convivência familiar:

É tudo, é a base de tudo. Se você não tiver pessoas como pai, mãe mais experientes na família, você perde tudo na vida. Então, eu acho que família é tudo, porque você sabe que vai ter apoio. (Maçã, 24 anos)

Família é o conjunto, não sei responder muito bem, acho que é apoio, união tudo aquilo que é bom, companheirismo. (Pêra, 30 anos)

Na categoria Aderência ao programa de planejamento familiar e na subcategoria $A$ percepção do acolhimento da equipe de enfermagem, traduz-se o quanto a equipe de enfermagem é valorizada pelas mulheres com relação ao PF. Porém, elas referem a própria falta de conscientização para seguir o programa e ouvir os aconselhamentos da equipe.

Nesta categoria está inserido o sistema de cuidado proposto por Leininger ${ }^{(5)}$, no qual se articulam os saberes populares e saberes profissionais, intermediados pela equipe de enfermagem. É a partir desses sistemas que a mulher/família toma as decisões de cuidado à saúde com ações conscientes de prevenção e programação da família que desejam constituir:

[...] conversei com as gurias aqui do posto e elas me ajudaram muito, e hoje nada mais me faz esquecer a reunião de planejamento familiar. Agora tenho três filhos. Se eu soubesse o que sei hoje não teria; é só saber tomar os remédios e não esquecer. É preciso usar a cabeça e se prevenir. Hoje em dia, se você pensar, é fácil viver. (Ameixa, 38 anos)
Trabalhar com a saúde da mulher é ter uma visão ampla do cuidado que ela necessita, e o PF situa-se como um conjunto de ações preventivas e educativas de atenção à mulher/família, que inclui como atividades básicas a assistência à concepção e contracepção.

O acolhimento é bom. Tudo que você precisa eles te ajudam, até mesmo nos exames que são mais difíceis, eles ajudam. (Maçã, 24 anos)

[...] o atendimento é bom porque sempre que eu preciso eles cuidam de mim, me atendem bem, têm carinho com as pessoas e explicam tudo direitinho. E isso é bom pra nós. (Morango, 40 anos)

Na subcategoria Facilidades e dificuldades percebidas diante do planejamento familiar é possível apreender que as mulheres sentem mais dificuldades do que facilidades para enfrentar e administrar o planejamento da família. As facilidades estão relacionadas à proximidade da Unidade de Saúde, o desejo de ter mais filhos, a aceitação do casal para o espaçamento dos filhos e a possibilidade de fazer a laqueadura:

No começo foi muito difícil, porque meus pais me educaram de uma forma diferente. Cresci na roça e prá eles eu tinha que ter muitos filhos. Agora que eu vim na cidade, tudo mudou, aprendi muito e hoje tenho só dois filhos. E é fácil pra mim, porque moro perto do postinho. (Morango, 40 anos)

Eu não tenho dificuldade. Eu queria ter mais filhos, por isso não tomo nada. (Mamão, 23 anos)

Entre as dificuldades, as mulhres apontam a fuga às regras estabelecidas pelo programa de $\mathrm{PF}$, justificando a falta de tempo, família desunida, falta de valorização de si mesma, e de ajuda do companheiro, dificuldades financeiras, de ir ao médico, de adesão e de continuidade no uso dos métodos contraceptivos:

Acho que minha maior dificuldade é ir ao médico e conseguir tomar os remédios sem parar, porque no terceiro filho eu não aguentei mais e engravidei logo. O que eu queria era conseguir satisfazer minhas necessidades. (Laranja, 26 anos)

Na categoria Auxílio da equipe de enfermagem e de saúde no planejamento familiar e na subcategoria Facilidade de acesso aos métodos, o PF foi definido pelas entrevistadas como meio para adquirir os dife- 
rentes métodos contraceptivos, e que o acesso, tanto aos métodos temporários quanto aos definitivos, é um direito que toda mulher tem. Contudo, baseandose em suas falas, podemos afirmar que os métodos disponibilizados para essas mulheres são limitados e encontram-se aquém de suas demandas:

Não é tão fácil porque primeiro você tem que passar pela consulta, ver se é bom o método, se não te faz mal. Só assim você consegue. (Maçã, 24 anos)

As ações educativas em saúde objetivam capacitar indivíduos ou grupos, de modo que eles possam assumir ou ajudar na melhoria das condições de saúde da população. A partir do levantamento do histórico das mulheres foi possível perceber as dimensões envolvidas para então, estabelecer prioridades de cuidado, levando em consideração a mediação do enfermeiro entre os sistemas popular e profissional. Portanto, para qualificar as informações às usuárias, é preciso promover medidas concretas e modificar a prática atualmente desenvolvida ${ }^{(15)}$.

\section{CONSIDERAÇÕES FINAIS}

O trabalho permitiu conhecer a realidade, facilidades e dificuldades na implementação de estratégias de PF. A análise dos depoimentos das mulheres aponta distintas vertentes do viver humano que compõem as estratégias para o PF e sua articulação com a qualidade de vida. Os aspectos culturais foram fortemente evidenciados, o que denota que as diversas conformações de família têm seu modo próprio de viver e de administrar conceitos de cuidado à saúde.

Para planejar o número de filhos não basta a escolha de um método anticoncepcional adequado à saúde $\mathrm{e}$ às convicções do casal; é preciso que haja um acordo maduro entre ambos. O PF é um conceito multidimensional com interpretações e usos variados pelos seus usuários, dadas as características do contexto e condições muito específicas de cada grupo populacional. Chamamos a atenção para as oportunidades de informação perdidas na prática assistencial. Vale ressaltar que para proporcionarmos uma assistência à saúde com qualidade é necessário entender cada indivíduo como um ser único, pertencente a um contexto social, cultural e familiar que condiciona diferentes formas de viver e adoecer.

Esta contextualização demonstra a fragilidade do cuidado à mulher/família executado pela equipe de saúde, pois a tomada de decisões sobre a reprodução não deve ser vista apenas sob o olhar da Enfermagem ou dos profissionais da área de saúde. Tais decisões dependem, também, das condições culturais, muitas vezes dos padrões de convívio e do modo que a mulher vive no círculo familiar e de seu contexto.

É preciso considerar ainda as diversidades e universalidades em relação a visões de mundo, estrutura social e outras dimensões, descobrindo, desta forma, meios de prover cuidar/cuidado que sejam congruentes às pessoas de diferentes culturas. Estudos devem ser realizados para dar continuidade nos desvelamentos das vivências de mulheres/famílias e articulados a referenciais teórico-metodológicos, a exemplo da Teoria de Leininger, que desafia os enfermeiros a utilizar o enfoque de cuidado transcultural na educação, pesquisa e prática de Enfermagem.

\section{REFERÊNCIAS}

1. Faúndes A, Hardy E. Ética médica e planejamento familiar no Brasil. Rev Bioet. 1996;4(2):1-3.

2. Ministério da Saúde (BR). Secretaria de Políticas de Saúde. Área Técnica de Saúde da Mulher. Assistência em Planejamento Familiar: Manual Técnico. $4^{\mathrm{a}}$ ed. Brasília: Ministério da Saúde; 2002.

3. Lohman AA. Planejamento da família: problemas e perspectivas. Rio de Janeiro: Saga; 1968.

4. George JB. Madeleine Leininger. Porto Alegre: Artes Médicas; 1993. Teorias de enfermagem: os fundamentos para a prática profissional. p. 286-99.

5. Rodrigues GC. Planejamento familiar. São Paulo: Ática; 1990.

6. Trindade MJ. Direitos sexuais e reprodutivos em cuidados de saúde primários. Rev Port Sex Planej Fam. 2002;(34):11-3.

7. Germano RM. Educação e ideologia da enfermagem no Brasil. $3^{\mathrm{a}}$ ed. São Paulo: Cortez; 1993.

8. Helman CG. Cultura, saúde e doença. $2^{\mathrm{a}}$ ed. Porto Alegre: Artes Médicas; 2003.

9. Centa ML, Pereira MTF. A relevância da cultura no cuidado das famílias. Fam Saúde Desenvolv. 2005;7(1):61-2.

10. Sousa LJX, Barroso MGT. Envenenar é mais perigoso: uma abordagem etnográfica. Cogitare Enferm. 1998;3(1):14-5. 
11. Minayo MCS. O desafio do conhecimento: pesquisa qualitativa em saúde. $10^{\mathrm{a}}$ ed. São Paulo: Hucitec; 2007.

12. Ministério da Saúde (BR). Conselho Nacional de Saúde. Diretrizes e normas regulamentadoras de pesquisa envolvendo seres humanos. Resolução n. 196 de 10 de outubro de 1996. Brasília; 1996.

13. Martins M, Viana CL, Geber S. Ginecologia. $2^{\mathrm{a}}$ ed. Rio de Janeiro: Medsi; 2001.

14. Romanelli G. Famílias de classes populares: socialização e identidade masculina. Cad Pesqui NEP. 1997;1(2):25-34.

15. Kawamoto EE. Educação em saúde. São Paulo: EPU; 1993. Enfermagem comunitária. p. 29-33. 